\title{
Comparison of dexmedetomidine and remifentanil for attenuation of hemodynamic responses to laryngoscopy and tracheal intubation
}

Jeong Han Lee, Hyojoong Kim, Hyun-Tae Kim, Myoung-Hun Kim, Kwangrae Cho, Se Hun Lim, Kun Moo Lee, Young-Jae Kim, and Chee-Mahn Shin

Department of Anesthesiology and Pain Medicine, Busan Paik Hospital, College of Medicine, Inje University, Busan, Korea

Background: This study was designed to compare the effect of dexmedetomidine and remifentanil used in anesthetic induction on hemodynamic change after direct laryngoscopy and tracheal intubation.

Methods: A total of 90 ASA class 1 or 2 patients were randomly assigned to one of 3 groups to receive one of the following treatments in a double-blind manner: normal saline (Group C, $\mathrm{n}=30$ ), dexmedetomidine $1 \mu \mathrm{g} / \mathrm{kg}$ (Group $\mathrm{D}, \mathrm{n}=30$ ), remifentanil $1 \mu \mathrm{g} / \mathrm{kg}$ (Group R, $\mathrm{n}=30$ ). Anesthesia was induced with propofol $2 \mathrm{mg} / \mathrm{kg}$ and rocuronium $0.6 \mathrm{mg} / \mathrm{kg}$ and maintained with 2 vol\% sevoflurane and $50 \%$ nitrous oxide in oxygen. In group D, dexmedetomidine $1 \mu \mathrm{g} / \mathrm{kg}$ was infused for $10 \mathrm{~min}$ before tracheal intubation. Patients in group R was received $1 \mu \mathrm{g} / \mathrm{kg}$ of remifentanil 1 minute before tracheal intubation. The systolic blood pressure, diastolic blood pressure and heart rate were recorded from entrance to operation room to $5 \mathrm{~min}$ after tracheal intubation.

Results: The percent increase in systolic and diastolic blood pressure due to tracheal intubation in group D and R were significantly lower than that of group $\mathrm{C}(\mathrm{P}<0.05)$. The heart rate $1 \mathrm{~min}$ after tracheal intubation was lower in groups $\mathrm{R}$ and $\mathrm{D}$ than in the group $\mathrm{C}(\mathrm{P}<0.05)$.

Conclusions: In healthy normotensive patients, the use of dexmedetomidine during anesthetic induction suppressed a decrease in blood pressure due to anesthetic induction and blunted the hemodynamic responses to endotracheal intubation. (Korean J Anesthesiol 2012; 63: 124-129)

Key Words: Dexmedetomidine, Endotracheal intubation, Hemodynamics, Remifentanil.

Received: January 4, 2012. Revised: 1st, February 14, 2012; 2nd, March 14, 2012. Accepted: March 20, 2012.

Corresponding author: Jeong Han Lee, M.D., Department of Anesthesiology and Pain Medicine, Busan Paik Hospital, College of Medicine, Inje University, Gaegeum 2-dong, Busanjin-gu, Busan 614-735, Korea. Tel: 82-51-890-6520, Fax: 82-51-898-4216, E-mail: ljh646@daum.net (c) This is an open-access article distributed under the terms of the Creative Commons Attribution Non-Commercial License (http:// creativecommons.org/licenses/by-nc/3.0/), which permits unrestricted non-commercial use, distribution, and reproduction in any medium, provided the original work is properly cited. 


\section{Introduction}

Laryngoscopic manipulation and endotracheal intubation, for anesthetic induction, increases the release of catecholamine by stimulating the sympathetic nervous system, which results in the elevation of blood pressure, heart rate, and arrhythmia $[1,2]$. This response could lead to severe situations like myocardial ischemia for patients who have risk factors of hypertension and ischemic heart diseases [3]. For these reasons, local anesthetics, beta blockers, and opioids have been used in order to prevent changes in the cardiovascular system when endotracheal intubation is carried out [4-6].

Fentanyl, sufentanil and other opioid agents have been studied to prevent cardiovascular changes due to interventions associated with anesthesia. However, remifentanil, the most recently introduced opioid, serves as an adequate opioid due to a small volume of distribution, and its rapid clearance in cases of endotracheal intubation; in which dynamic hemodynamic changes can occur within a short period of time [7].

Clonidine, which is an alpha-2 agonist, is known to decrease the reaction of the sympathetic nervous system and inhibit cardiovascular changes against adverse actions $[8,9]$. The recently introduced alpha- 2 agonist, dexmedetomidine, is a more effective alpha- 2 agonist than clonidine. The ratio of $\alpha 2: \alpha 1$ for dexmedetomidine is $1,620: 1$, which is higher than clonidine, where the ratio is $220: 1$. In addition, dexmedetomidine is faster acting than clonidine [10]. In addition, some studies have reported that dexmedetomidine reduces hemodynamic changes during anesthetic induction and surgery $[11,12]$. There have been few studies that have compared dexmedetomidine and other existing drugs. In this regard, the authors carried out this study to investigate the effects of dexmedetomidine and remifentanil on the hemodynamic changes, when endotracheal intubation is performed with a laryngoscope.

\section{Materials and Methods}

For this study, 90 adult patients varying in ages from 18 to 60 years old, who were further categorized by one and 2 of the American Society of Anesthesiologists class, were targeted. After

Table 1. Demographic Data

\begin{tabular}{lccc}
\hline & Group D (n=30) & Group R $(\mathrm{n}=30)$ & Group C (n=30) \\
\hline Sex (M/F) & $15 / 15$ & $15 / 15$ & $15 / 15$ \\
Age (yr) & $37.8 \pm 11.3$ & $37.8 \pm 11.7$ & $36.0 \pm 12.4$ \\
Weight (kg) & $63.9 \pm 9.8$ & $63.6 \pm 10.7$ & $62.5 \pm 11.8$ \\
Height (cm) & $166.3 \pm 7.2$ & $165.3 \pm 7.9$ & $166.9 \pm 8.9$ \\
\hline
\end{tabular}

Values are mean \pm SD or number of patients. There was no significant difference among groups. Group D: dexmedetomidine $1 \mu \mathrm{g} / \mathrm{kg}$, Group R: remifentanil $1 \mu \mathrm{g} / \mathrm{kg}$, Group C: normal saline. the clinical research ethics committee at our hospital approved this study, we explained the aim and the method of this study to patients during a preanesthetic visit. We excluded patients who had cardiovascular, neurologic, respiratory, and liver diseases, or who were morbidly obese. If patients who were unable to maintain an airway or attempted endotracheal intubation more than twice were also excluded. The patients were randomly assigned into group C (normal saline), group D (dexmedetomidine), or group $\mathrm{R}$ (remifentanil). There were no statistically significant differences in gender, age, height, or weight between the groups (Table 1).

All patients had been fasting for more than 8 hours before surgery, and they were not premedicated in an effort to reduce errors caused by drug interactions or the presence of a cardiovascular response. After entering the operating room, patients were attached to an EKG, a pulse oxymeter, an automated noninvasive pressure device, or BIS (bispectral index) to screen their vital signs. After evaluating their initial vital signs, $1 \mu \mathrm{g} / \mathrm{kg}$ of dexmedetomidine was administered to the patients in group $\mathrm{D}$ for a $10 \mathrm{~min}$ time period, and the same volume of saline was injected to the patients in groups $\mathrm{R}$ and $\mathrm{D}$. Pre-oxygenation was performed with $100 \%$ oxygen, and $2 \mathrm{mg} / \mathrm{kg}$ of propofol was administered over the course of 30 seconds to the patients in all groups, 6 min after evaluating their initial vital signs. We injected rocuronium $(0.6 \mathrm{mg} / \mathrm{kg})$ after confirming a lack of response to voice and a loss of eyelid reflex.

Patients in group $\mathrm{R}$ received $3 \mathrm{ml}$ of remifentanil $(1 \mu \mathrm{g} /$ $\mathrm{kg}$ ) mixed with saline solution, 1 minute before endotracheal intubation, and the same volume of saline solution was intravenously injected to patients in group D and the control group. One minute after the injections of medication, we carried out endotracheal intubation with a laryngoscope, and evaluated the systolic and diastolic blood pressure, as well as heart rate per minute for the duration of $5 \mathrm{~min}$ after performing the intubation. An anesthesiologist, who did not know what kind of medication was being administered, performed the endotracheal intubation in each patient and maintained the anesthesia with 2 vol\% sevoflurane and $50 \%$ nitrous oxide, after intubation.

According to Zhang and Sun [13], changes in the systolic blood pressure after an intubation procedure was 6 on average, and the standard deviation 10, when remifentanil was utilized. Menda et al. [14] showed that no significant difference was found between group $\mathrm{D}$ and the control group, $5 \mathrm{~min}$ after the intubation.

Consequently, we assumed that the changes in systolic blood pressure would be 6 on average, with a standard deviation of 12 , as well as a revised level of significance in order to compare the 3 treatment groups. Based on a statistical power of $80 \%$ and a significance level of $0.05,26$ patients in each group were selected to perform the research. Given a dropout rate, an 
additional 30 subjects were included in each group.

We compiled statistics on the evaluated data using SPSS version 18.0 (SPSS Inc, Chicago, IL, USA), and marked the results with \pm standard deviation. With a one way ANOVA, we analyzed the demographic data and evaluated the data for each group. The blood pressure and heart rate in each group were evaluated by repeated measures of ANOVA, and post hoc analysis was performed with the Scheffe's test. When the results were $\mathrm{P}<0.05$, we assessed them as significant statistical numbers.

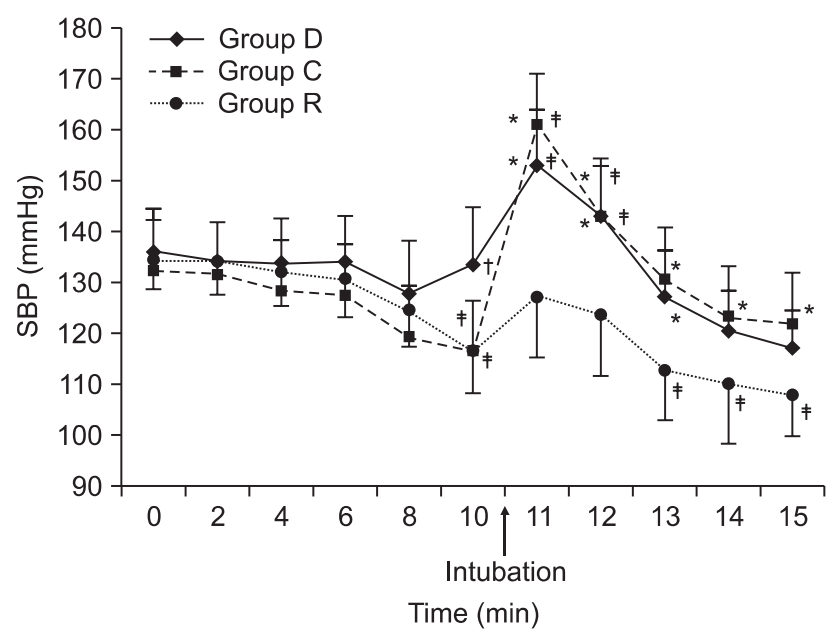

Fig. 1. Changes of systolic blood pressure from baseline to $5 \mathrm{~min}$ after tracheal intubation. Group D: dexmedetomidine $(1 \mu \mathrm{g} / \mathrm{kg})$, Group R: remifentanil ( $1 \mu \mathrm{g} / \mathrm{kg})$, Group C: normal saline, SBP: systolic blood pressure, *P $<0.05$ compared with Group $\mathrm{R},{ }^{\dagger} \mathrm{P}<0.05$ compared with Group R and C, ${ }^{\ddagger} \mathrm{P}<0.05$ compared with baseline.

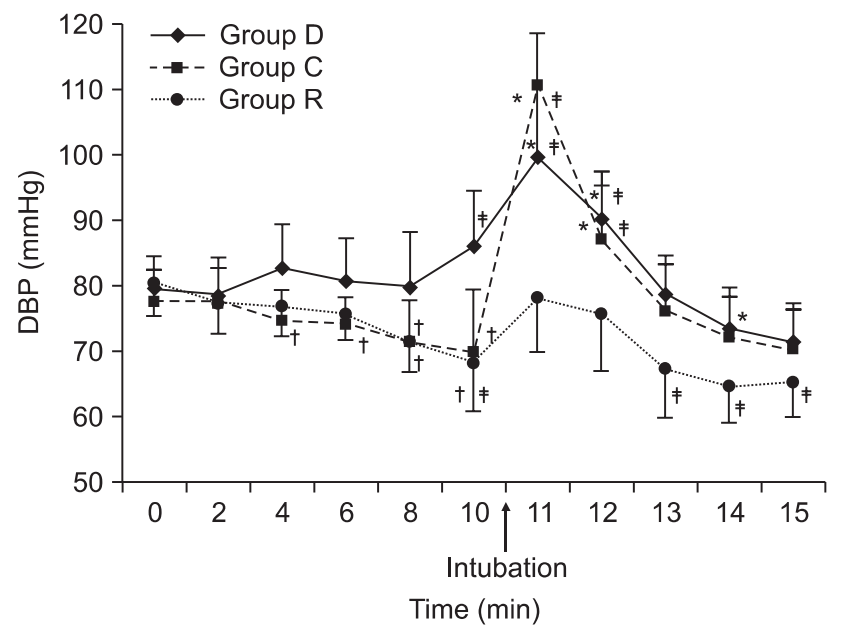

Fig. 2. Changes of diastolic blood pressure from baseline to $5 \mathrm{~min}$ after tracheal intubation. Group D: dexmedetomidine $(1 \mu \mathrm{g} / \mathrm{kg})$, Group R: remifentanil ( $1 \mu \mathrm{g} / \mathrm{kg})$, Group C: normal saline, DBP: diastolic blood pressure, ${ }^{*} \mathrm{P}<0.05$ compared with Group $\mathrm{R},{ }^{\dagger} \mathrm{P}<0.05$ compared with Group D, ${ }^{\ddagger} \mathrm{P}<0.05$ compared with baseline.

\section{Results}

The systolic and diastolic blood pressure, and the heart rate, within each group that was evaluated after entering the operating room, showed no considerable differences. Furthermore, the patients in this study did not develop hypotension or bradycardia, which may have required further treatment procedures.

When it came to blood pressure, the diastolic blood pressure in group D was significantly higher than that of group C, which started 4 min after the infusion of dexmedetomidine, and 8 min later, the diastolic blood pressure in group D was significantly higher than, not only group $\mathrm{C}$, but that of group $\mathrm{R}$. The systolic and diastolic blood pressure in group $\mathrm{D}$ were significantly higher than that of both group $\mathrm{D}$ and group $\mathrm{C}$ at 10 $\mathrm{min}$, immediately before endotracheal intubation. The systolic and diastolic blood pressure in group $\mathrm{R}$, immediately after the intubation, was lower than the other 2 groups. In addition, the systolic blood pressure and diastolic blood pressure in group D were lower than those of group C, which was found not to be statistically significant (Fig. 1 and 2).

The heart rate in group D was significantly lower than other groups starting at $4 \mathrm{~min}$ after the infusion of dexmedetomidine to $10 \mathrm{~min}$ immediately before endotracheal intubation. After the intubation, the heart rate in group $\mathrm{C}$ remained significantly high compared to the other groups, but there were no significant differences between groups $\mathrm{R}$ and $\mathrm{D}$ (Fig. 3).

The systolic blood pressure and diastolic blood pressure in group R showed a significant decrease immediately before the intubation, and only the systolic blood pressure in group

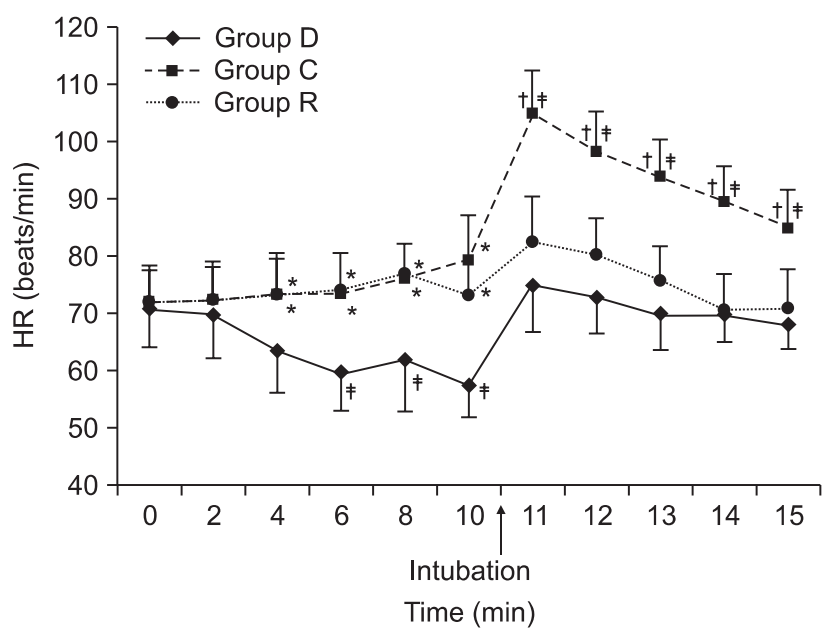

Fig. 3. Changes of heart rate from baseline to $5 \mathrm{~min}$ after tracheal intubation. Group D: dexmedetomidine $(1 \mu \mathrm{g} / \mathrm{kg})$, Group R: remifentanil $(1 \mu \mathrm{g} / \mathrm{kg})$, Group C: normal saline, HR: heart rate, $* \mathrm{P}<0.05$ compared with Group D, ${ }^{\dagger} \mathrm{P}<0.05$ compared with Group D and Group $\mathrm{R},{ }^{\ddagger} \mathrm{P}<0.05$ compared with baseline. 
Table 2. Hemodynamic Changes after Tracheal Intubation

\begin{tabular}{|c|c|c|c|c|}
\hline & & $\begin{array}{c}\text { Group D } \\
(\mathrm{n}=30)\end{array}$ & $\begin{array}{l}\text { Group R } \\
(\mathrm{n}=30)\end{array}$ & $\begin{array}{c}\text { Group C } \\
(\mathrm{n}=30)\end{array}$ \\
\hline \multirow[t]{3}{*}{ SBP } & 1 min before tracheal intubation & $133.5 \pm 22.4$ & $116.5 \pm 16.4$ & $116.1 \pm 23.6$ \\
\hline & 1 min after tracheal intubation & $153.1 \pm 21.6$ & $127.2 \pm 24.2$ & $160.9 \pm 17.6$ \\
\hline & Percentile change & $14.6 \%$ & $9.2 \%$ & $38.6 \% *$ \\
\hline \multirow[t]{3}{*}{ DBP } & 1 min before tracheal intubation & $86.3 \pm 16.4$ & $68.2 \pm 14.4$ & $70.0 \pm 19.0$ \\
\hline & 1 min after tracheal intubation & $99.9 \pm 21.4$ & $78.3 \pm 16.4$ & $110.6 \pm 15.8$ \\
\hline & Percentile change & $15.7 \%$ & $14.8 \%$ & $58.0 \% *$ \\
\hline \multirow[t]{3}{*}{ HR } & $1 \mathrm{~min}$ before tracheal intubation & $57.4 \pm 11.0$ & $73.2 \pm 13.2$ & $79.3 \pm 16.0$ \\
\hline & 1 min after tracheal intubation & $74.9 \pm 16.4$ & $82.6 \pm 15.4$ & $105.1 \pm 14.4$ \\
\hline & Percentile change & $30.4 \%$ & $12.8 \%$ & $32.6 \%^{\dagger}$ \\
\hline
\end{tabular}

Values are mean \pm SD. Group D: dexmedetomidine $1 \mu \mathrm{g} / \mathrm{kg}$, Group R: remifentanil $1 \mu \mathrm{g} / \mathrm{kg}$, Group C: normal saline. SBP: systolic blood pressure, DBP: diastolic blood pressure, HR: heart rate, $* \mathrm{P}<0.05$ compared with Group R and $\mathrm{D},{ }^{\dagger} \mathrm{P}<0.05$ compared with Group R.

C significantly decreased when compared to the baselines for each of the groups. However, the diastolic blood pressure in group $\mathrm{D}$, actually increased during the same period and the HR, in only group D, significantly decreased. No significant difference was found between the other two groups. The systolic blood pressure, diastolic blood pressure, and heart rate, among all 3 groups, significantly increased immediately after endotracheal intubation, but the increasing range of blood pressure in group $\mathrm{C}$ was considerably wider than that of the other 2 groups. Group $\mathrm{C}$ showed a significant increase in range of heart rate in comparison to group D (Table 2).

\section{Discussion}

This study is designed to compare the effect of preventing cardiovascular response of dexmedetomidine to that of remifentanil, which is known to reduce cardiovascular response during endotracheal intubation. The latter finding is based on measurements from other studies.

The sympathetic nervous system is provoked by insertion of a laryngoscope and by endotracheal intubation, which can lead to severe tachycardia, hypertension, or arrhythmia [1]. As a result, anesthesiologists have been concerned about reducing the reduction of these hemodynamic changes and thus have begun their studies.

Remifentanil is analogous to the fentanyl structure and is a strong $\mu$ receptor agonist. It is useful in situations requiring endotracheal intubation and in cases in which severe stimulation may occur within a short-time. In addition, it can be infused on a continuous basis, since it is rarely accumulated in the body due to its rapid action and metabolism [7].

Lee et al. [15] reported that $1 \mu \mathrm{g} / \mathrm{kg}$ of remifentanil was an optimal dose to attenuate hemodynamic changes, when thiopental and sevoflurane are used for anesthesia. Min et al. [16] also found that $1 \mu \mathrm{g} / \mathrm{kg}$ of remifentanil successfully prevented hemodynamic fluctuations without any further com- plications after rapid sequence induction. Some complications of remifentanil were reported; unexpected hypotension, bradycardia, hypoventilation, and muscle rigidity could occur during endotracheal intubation [16]. In our study, $1 \mu \mathrm{g} / \mathrm{kg}$ of remifentanil was administered. As a result, blood pressure was maintained below the baseline during the period of anesthetic induction, and hypotension or bradycardia, which may appear during the treatment, did not occur.

Dexmedetomidine is a very effective alpha-2 agonist and reportedly effective in stabilizing the cardiovascular system, as well as reducing the requirements for analgesics, sedatives, and anesthetics. Segal et al. [17] reported that the requirement for halothane decreased in cases where dexmedetomidine was used, and Aho et al. [18] stated that the requirement for isoflurane decreased up to $90 \%$ in a dose dependent manner.

In addition, Aantaa et al. [19] found that the dose of thiopental sodium, which was used in inducing anesthesia for the group injected with dexmedetomidine before anesthesia, was significantly lower compared to the control group. Dutta et al. [20] reported that the requirement of the anesthetics for a group injected with dexmedetomidine was smaller in the study where propofol was used for anesthetic induction.

Endotracheal intubation increases the concentration of catecholamine in the blood by stimulating the sympathetic nervous system, which results in an increase in heart rate and blood pressure [1]. Dexmedetomidine is known to decrease the concentration of catecholamine and in particular, norepinephrine in the blood, and inhibits the secretion of catecholamine against a noxious stimulus $[21,22]$. In addition, recent studies have reported that dexmedetomidine injected before performing endotracheal intubation improves hemodynamic changes. Jaakola et al. [11] found that the maximal blood pressure and heart rate in the group injected with $0.6 \mu \mathrm{g} / \mathrm{kg}$ of dexmedetomidine before anesthesia, were significantly lower than those of the control group; furthermore, Lawrence and De Lange [12] reported that the maximal blood 
pressure and heart rate in the group injected with $2 \mu \mathrm{g} / \mathrm{kg}$ of dexmedetomidine were considerably lower than those of the control group.

Substantial research has occurred that has tested a dose of 0.5 to $2 \mu \mathrm{g} / \mathrm{kg}$ of dexmedetomidine by injection, but Sağıroğlu et al. [23] found that $1 \mu \mathrm{g} / \mathrm{kg}$ of dexmedetomidine was more effective than $0.5 \mu \mathrm{g} / \mathrm{kg}$ of the same medication. In this regard, $1 \mu \mathrm{g} / \mathrm{kg}$ of dexmedetomidine was injected and the heart rate was significantly lower than the control group at 4 min after its injection. The systolic blood pressure and diastolic blood pressure, immediately after endotracheal intubation, were low, but they were not statistically considerable.

Kunisawa et al. [24] reported that an injection of dexmedetomidine inhibits a decrease in blood pressure caused by the anesthetics, and so postulated that it may be the result of vasoconstriction caused by the alpha- 2 receptor in the vascular smooth muscle. The report stated that blood pressure temporarily increases one minute after an injection with a loading dose of dexmedetomidine, and reaches its peak at 3 min. When dexmedetomidine is used in a combination with anesthetics, it reportedly prevents further drops in blood pressure and rather inhibits it [25].

Hall et al. [26] found that biphasic cardiovascular changes, where blood pressure decreased followed by a momentary rise in blood pressure after an injection of dexmedetomidine, occurred after constant injections of dexmedetomidine. They reported that an insignificant rise in blood pressure had continuously been exhibited for 10 min after an initial injection of dexmedetomidine, and the heart rate decreased significantly. The medication takes some time to attach to receptors in the vascular smooth muscle and to circulate towards the central nervous system in order to suppress the sympathetic nervous system.

In this study, blood pressure, after an injection of dexmedetomidine, was relatively high compared to the other 2 groups, and changes in blood pressure after the injection of anesthetics were minor. Consequently, we found that dexmedetomidine is effective in improving the fluctuations in blood pressure caused by anesthetics. In addition, fluctuations in blood pressure before and after endotracheal intubation were significantly minor compared to the control group, due to an increased blood pressure followed by biphasic changes. Nonetheless, we thought that maximal blood pressure showed no significant differences when compared to the control group.

Dexmedetomidine can cause bradycardia and hypotension, according to Erkola et al. [27]. In their study the patients in the group injected with dexmedetomidine developed bradycardia more frequently than those of the group injected with midazolam. Keniya et al. [28] reported that the patients in the group injected with $1 \mu \mathrm{g} / \mathrm{kg}$ of dexmedetomidine received more treatments for bradycardia than patients in the control group. In this study however, incidents of bradycardia when the heart rate was reduce less than 50 times/min did not occur, and no patients required treatment.

It has been reported that an increase of catecholamine, in cases of carrying out endotracheal intubation, varies depending on what kind of anesthetics are used. Misiolek et al. [29] found that propofol is more effective in inhibiting the reactions of catecholamines than thiopental, when they induced anesthesia.

In this study, when we carried out endotracheal intubation, hemodynamic changes, after a pre-medication of dexmedetomidine, showed no difference between the control groups. It is thought that propofol, which is effective in suppressing catecholamines, could play a variable role, but this study had its limitations in that we did not directly evaluate the catecholamines. In addition, Basar et al. [30] reported that the cardiac index decreased by $27.9 \%$ after an injection of dexmedetomidine $(0.5 \mu \mathrm{g} / \mathrm{kg})$. We assumed that more accurate result would be made if we evaluated the cardiac index or the cardiac output in our study.

In conclusion, dexmedetomidine significantly decreased the heart rate, as did remifentanil, after we observed how dexmedetomidine $(1 \mu \mathrm{g} / \mathrm{kg})$ and remifentanil $(1 \mu \mathrm{g} / \mathrm{kg})$ affected the hemodynamic changes when compared with the control group in cases of endotracheal intubation.

Therefore, maximal blood pressure in the groups injected with dexmedetomidine, immediately after the intubation, showed insignificant differences compared to the control group. However, we thought that this was caused by a significantly high blood pressure in group $\mathrm{D}$, immediately before the intubation, while an upward fluctuation of blood pressure before and after the intubation in the D group was significantly minor when compared to the control group. When dexmedetomidine was used in the group within a normal range of blood pressure, it was effective in preventing complications, such as a decrease in blood pressure caused by anesthetics and reduced hemodynamic changes in the event of endotracheal intubation.

\section{Acknowledgments}

This work was supported by Grant from Inje University, 2010.

\section{References}

1. Shribman AJ, Smith G, Achola KJ. Cardiovascular and catecholamine responses to laryngoscopy with and without tracheal intubation. Br J Anaesth 1987; 59: 295-9.

2. Edwards ND, Alford AM, Dobson PM, Peacock JE, Reilly CS. Myocardial ischaemia during tracheal intubation and extubation. Br J Anaesth 1994; 73: 537-9. 
3. Roy WL, Edelist G, Gilbert B. Myocardial ischemia during noncardiac surgical procedures in patients with coronary-artery disease. Anesthesiology 1979; 51: 393-7.

4. Stoelting RK. Blood pressure and heart rate changes during shortduration laryngoscopy for tracheal intubation: influence of viscous or intravenous lidocaine. Anesth Analg 1978; 57: 197-9.

5. Siedlecki J. Disturbances in the function of cardiovascular system in patients following endotracheal intubation and attempts of their prevention by pharmacological blockade of sympathetic system. Anaesth Resusc Intensive Ther 1975; 3: 107-23.

6. Stanley TH, Berman L, Green O, Robertson D. Plasma catecholamine and cortisol responses to fentanyl-oxygen anesthesia for coronary artery operations. Anesthesiology 1980; 53: 250-3.

7. Glass PS, Hardman D, Kamiyama Y, Quill TJ, Marton G, Donn KH, et al. Preliminary pharmacokinetics and pharmacodynamics of an ultra-short-acting opioid: remifentanil (GI87084B). Anesth Analg 1993; 77: 1031-40.

8. Hayashi Y, Maze M. Alpha 2 adrenoceptor agonists and anaesthesia. Br J Anaesth 1993; 71: 108-18

9. Ghignone M, Quintin L, Duke PC, Kehler CH, Cavillo O. Effects of clonidine on narcotic requirements and hemodynamic responses during intubation of fentanyl anesthesia and endotracheal intubation. Anesthesiology 1986; 64: 36-42.

10. Virtanen R, Savola JM, Saano V, Nyman L. Characterization of the selectivity, specificity and potency of medetomidine as an alpha 2adrenoceptor agonist. Eur J Pharmacol 1988; 150: 9-14.

11. Jaakola ML, Ali-Melkkilä TA, Kanto J, Kallio A, Scheinin H, Scheinin M. Dexmedetomidine reduces intraocular pressure, intubation responses and anaesthetic requirements in patients undergoing ophthalmic surgery. Br J Anaesth 1992; 68: 570-5.

12. Lawrence CJ, De Lange S. Effects of a single pre-operative dexmedetomidine dose on isoflurane requirements and perioperative haemodynamic stability. Anaesthesia 1997; 52: 736-44.

13. Zhang GH, Sun L. Peri-intubation hemodynamic changes during low dose fentanyl, remifentanil and sufentanil combined with etomidate for anesthetic induction. Chin Med J (Engl) 2009; 122: 2330-4.

14. Menda F, Köner O, Sayin M, Türe H, Imer P, Aykaç B. Dexmedetomidine as an adjunct to anesthetic induction to attenuate hemodynamic response to endotracheal intubation in patients undergoing fast-track CABG. Ann Card Anaesth 2010; 13: 16-21.

15. Lee JR, Jung CW, Lee JH, Choi IY, Seo KS, Kim HK, et al. Optimal dose of remifentanil to suppress cardiovascular responses to laryngoscopic endotracheal intubation. Korean J Anesthesiol 2005; 49: 780-5.

16. Min JH, Chai HS, Kim YH, Chae YK, Choi SS, Lee A, et al. Attenuation of hemodynamic responses to laryngoscopy and tracheal intubation during rapid sequence induction: remifentanil vs. lidocaine with esmolol. Minerva Anesthesiol 2010; 76: 188-92.

17. Segal IS, Vickery RG, Walton JK, Doze VA, Maze M. Dexmedetomidine diminishes halothane anesthetic requirements in rats through a postsynaptic alpha 2 adrenergic receptor. Anesthesiology
1988; 69: 818-23.

18. Aho M, Lehtinen AM, Erkola O, Kallio A, Korttila K. The effect of intravenously administered dexmedetomidine on perioperative hemodynamics and isoflurane requirements in patients undergoing abdominal hysterectomy. Anesthesiology 1991; 74: 997-1002.

19. Aantaa R, Kanto J, Scheinin M, Kallio A, Scheinin H. Dexmedetomidine, an alpha 2-adrenoreceptor agonist, reduces anesthetic requirements for patients undergoing minor gynecologic surgery. Anesthesiology 1990; 73: 230-5.

20. Dutta S, Karol MD, Cohen T, Jones RM, Mant T. Effect of dexmedetomidine on propofol requirements in healthy subjects. J Pharm Sci 2001; 90: 172-81.

21. Kallio A, Scheinin M, Koulu M. Effects of dexmedetomidine, a selective alpha 2-adrenoceptor agonist, on hemodynamic control mechanisms. Clin Pharmacol Ther 1989; 46: 33-42.

22. Jalonen J, Hynynen M, Kuitunen A, Heikkila H, Perttila J, Salmenpera $\mathrm{M}$, et al. Dexmedetomidine as an anesthetic adjunct in coronary artery bypass grafting. Anesthesiology 1997; 86: 331-45.

23. Sağıroğlu AE, Celik M, Orhon Z, Yüzer S, Sen B. Different doses of dexmedetomidine on controllıng haemodynamic responses to tracheal intubation. The Internet Journal of Anesthesiology 2010 Vol. 27 Number 2. Available from http://www.ispub.com/journal/ the-internet-journal-of-anesthesiology/volume-27-number-2/ d-fferent-doses-of-dexmedetomidine-on-controll-ng-haemodynam-c-responses-to-tracheal-intubat-on.html.

24. Kunisawa T, Nagata O, Nagashima M, Mitamura S, Ueno M, Suzuki A, et al. Dexmedetomidine suppresses the decrease in blood pressure during anesthetic induction an blunts the cardiovascular response to tracheal intubation. J Clin Anesth 2009; 21: 194-9.

25. Bloor BC, Ward DS, Belleville JP, Maze M. Effects of intravenous dexmedetomidine in humans. II. Hemodynamic changes. Anesthesiology 1992; 77: 1134-42.

26. Hall JE, Uhrich TD, Barney JA, Arain SR, Ebert TJ. Sedative, amnestic, and analgesic properties of small-dose dexmedetomidine infusions. Anesth Analg 2000; 90: 699-705.

27. Erkola O, Korttila K, Aho M, Haasio J, Aantaa R, Kallio A. Comparison of intramuscular dexmedetomidine and midazolam premedication for elective abdominal hysterectomy. Anesth Analg 1994; 79: 646-53.

28. Keniya VM, Ladi S, Naphade R. Dexmedetomidine attenuates sympathoadrenal response to tracheal intubation and reduces perioperative anaesthetic requirement. Indian J Anaesth 2011; 55: 3527.

29. Misiolek H, Wojcieszek E, Dyaczynska-Herman A. Comparison of influence of thiopentone, propofol and midazolam on blood serum concentration of noradrenaline and cortisol in patients undergoing non-toxic struma operation. Med Sci Monit 2000; 6: 319-24.

30. Basar H, Akpinar S, Doganci N, Buyukkocak U, Kaymak C, Sert O, et al. The effects of preanesthetic, single-dose dexmedetomidine on induction, hemodynamic and cardiovascular parameters. J Clin Anesth 2008; 20: 431-6. 